\title{
The Association Between Parents' Socio-Economic Status and the Level of Religiosity Among Undergraduates
}

\author{
Olatunji Olabimpe Ajoke ${ }^{1} \&$ Idemudia Erhabor Sunday ${ }^{1}$ \\ ${ }^{1}$ Faculty of Humanities, North-West University, South Africa \\ Correspondence: Olatunji Olabimpe Ajoke, Faculty of Humanities, North-West University, South Africa. E-mail: \\ ajoke.olatunji@fuoye.edu.ng
}

Received: September 24, 2019 Accepted: October 23, 2019 Online Published: November 14, 2019

doi:10.5539/gjhs.v11n13p98

URL: https://doi.org/10.5539/gjhs.v11n13p98

\begin{abstract}
This study assessed the influence of parents' socio-economic status on the level of religiosity in a sample of Nigerian undergraduates. A convenience sample of 200 students (mean age $=20.41 \pm 2.54$ ) participated in the study. Two structured scales were used which included Kuppuswanny's scale and Duke University Religiosity Index. Data were analysed using one way ANOVA. Findings showed that the parental education, occupation and income significantly influenced the level of religiosity. A follow-up post-hoc analysis using Fisher's LSD showed that participants whose parents were employed in non-professional occupation with lower education and poorer income were more religious compared to their counterparts whose parents had higher education, higher income and engaged in professional occupations. The study recommended that the upcoming generation of youth should utilize an objective, practical, and aggressive approach as a means to achieve better socio-economic and political transformation rather than using religion practises.
\end{abstract}

Keywords: socio-economic status; undergraduates, religiosity, parents, Nigeria

\section{Introduction}

It is increasingly difficult to ignore the role of the socio-economic status in the current level of religiosity in Nigeria because research has identified the impact of religiosity on economic outcomes (Tomalin, 2018; Abdussalam, Johari, \& Alias 2015; Aslam, 2014, Hogue, Khan, \& Mohammad, 2015; Beyes, 2014; Plouff \& Tremblay, 2017). Religion is an important cultural and universal social institution that has great influence on people's attitudes, values, and behaviours at both individual and societal levels, while religiosity is the degree to which religion is practised, which can encapsulate all forms and dimensions of religion practises. Religiosity can also be seen as an extreme view and over dedication to religious rituals and traditions (Gallagher \& Tierney 2013). Studies have shown that some religious practices are associated with low levels of depression (McBride, 2016), personal well-being (Koenig, 2012) and positive social attitude (Gebauer, Sedikidesc, \& Neberich, 2012). Despite the great endowment of Nigeria in terms of natural resources, there seems to be a serious challenge in her economic development which calls for serious concern considering the high level of poverty in the country (Action Aid Nigeria, 2015). It is noteworthy that a large proportion of her citizens occupy the low social economic ladder (Taiwo \& Agwu, 2016; Ucha, 2010).

Socio-economic status (SES) can be defined as a measure of one's combined economic and social status, which has been found to be positively associated with better health (Baker, 2014). There are three indicators for SES, which include education, income, and occupation. The measure of the socio-economic status of an individual is largely determined by the overall socio-economic status and position of the country in which he/she resides (Gallup, 2009). In survey research of 114 countries by Gallup (2009), it was discovered that the most highly religious countries are relatively poor with a per-capital GDP below $\$ 5000$, reflecting a strong relationship between a country's SES and the level of religiosity of the residents. When there are disequilibrium in the economic, political, and social spheres of a country, the consequences of such on the citizens are a high level of stress, unemployment and poverty (Tomalin, 2018). In most developing countries with high level religiosity, there are deficiencies in capital and material resources which inhibit the optimal realization of basic needs such as food, health, education, shelter, and clothing (Ighadalo, 2012, United Nations, 1998). Many of the crimes that are common in Nigeria which include armed robbery, kidnapping, human trafficking, and various insurgencies may be linked to low socio-economic status (Ayegba, 2015). 


\subsection{Current Work}

Nigeria is one of the most religious countries in the world (Gallup, 2009), and as such, her citizens turn to faith and belief in God as their trust and hope in government declines. Even though religion institutions remain one of the major stakeholders in poverty alleviation in the country, the high level of religiosity might have reduced the political awareness of her citizens in such a way that Nigerians do not see the government as an agent of social change, and that which possesses instrument for providing better social and economic conditions, but instead, they see religion as a function of social change. Thus, there is a high rate of religiosity as the people go deeper into religious practises because they feel that pastors know what they needed most. Due to the proximity of religion to the people, religious values and practises are to a great extent major determinants in the drive to establish a balanced socio-economic status of an individual. Religious institutions have always played a central role in supporting people experiencing poverty through service delivery and provision of spiritual resources that provide mechanisms for resilience at both individual and community level. Some of the service deliveries include the establishment of schools and scholarship schemes, building of hospitals and provision of medical services, provision of orphanages, old people and motherless homes, empowerment of women or other vulnerable groups and many others. Few studies (Aslam, 2014; Abdussalam, Johari, \& Alias, 2015; Taiwo \& Agwu, 2016) conducted in Nigeria have researched into the role played by religion in alleviating poverty in the country. These works affirmed that religion creates a new matrix of thought in influencing the values of the society. Increasing evidence supports the link between SES and negative psychological health outcomes, attention-deficit hyperactivity disorder, depression and conduct disorder (Goodman, 1999; Businelle et al., 2013) while higher levels of SES is associated with more positive psychological outcomes like optimism, self-esteem and control (Fassbender \& Leyendecker, 2018). Given this fact, it should be expected that the high rate of religiosity in Nigeria could be a form of coping strategy, last resort to reducing tension and stress among the citizens. This study seeks to establish whether SES positively relates to the level of religiosity among students in a tertiary institution. The study also seeks to establish if there will be a significant difference between participants with a higher socio-economic background as compared with those on lower socio-economic background.

\section{Method}

\subsection{Study Design}

This was a correlational study that employed an ex-post facto research design. The choice of this design was based on the ground that the independent variable was not actively manipulated. The independent variable was Socio-Economic Status (SES) while the dependent variable was the level of religiosity.

\subsection{Participants and Sampling Techniques}

A convenience sample of 200 undergraduates in a Nigerian university participated in the study. Participants were male $(58 \% \mathrm{~N}=115)$ and female $(42 \% \mathrm{~N}=85)$ with ages ranging between 15 and $30(\mathrm{M}=20.41, \mathrm{SD}=2.54)$. They were full-time students dependent on their parents for upkeeps and payments of school fees. The composition of the year of study for participants included for first year $(45 \% \mathrm{~N}=90)$, second-year $(26 \% \mathrm{~N}=52)$, third-year $(17 \%$, $\mathrm{N}=34)$, fourth-year $(20 \%, \mathrm{~N}=10)$ and fifth year $(2 \%, \mathrm{~N}=4)$.

\subsection{Measures}

Structured questionnaires were used to collect data. The questionnaire comprised relevant information on respondents' socio-demographic characteristics, reliable scales on SES, and religiosity. In the questionnaire, religiosity was measured by the Duke University Religiosity Index (DUREL) developed by Koenig and Bussing (2010). It is a five-item scale with the following samples: "How often do you attend church, or other religious meetings" and "My religious beliefs are what really lie behind my whole approach to life". The authors reported internal consistency reliability with a Cronbach's alpha coefficient of .91 . The current study obtained alpha coefficient of .88. In the same questionnaire, SES was measured by Kuppuswanny's scale developed by Kuppuswanny (1981) and revised by (Kumar, Gupta, \& Kishore, 2012). The scale comprised three sections of 7 items each. The scale used education, occupation, and monthly income of the head of the family to calculate the socio-economic status of respondents. The authors reported internal consistency reliability with a Cronbach's alpha coefficient between .78 and .91 . We obtained .81 alpha coefficient in the present study.

\subsection{Statistical Analyses}

Data were analyzed by the aid of IBM SPSS statistics version 21.0 for windows (SPSS Inc., Chicago, IL). One way ANOVA was used to calculate the differences of SES on religiosity level while the Fisher's LSD was used to test the direction of the difference. 


\section{Results}

The data collected were scored and analysed. The following are the results:

\subsection{Descriptive Statistics}

Data on socio-demographics showed that the family monthly income in thousands (Naira) included: 100 and below $(27.5 \% \mathrm{~N}=55), 100-200(25 \% \mathrm{~N}=50), 200-300(12.5 \% \mathrm{~N}=25)$, Greater than $300(35 \% \mathrm{~N}=70)$. The head of the family educational status included: Postgraduate $(17 \% \mathrm{~N}=33)$, Higher National Diploma/ Bachelor degree (HND/BSC) $(46 \%, \mathrm{~N}=93)$, Ordinary National Diploma/National College of Education (OND/NCE) (18\% $\mathrm{N}=35)$, Secondary School Certificate (SSCE) and below (19\%, $\mathrm{N}=39)$. Occupation included: professionals (23\% $\mathrm{N}=46)$, other professionals $(36 \% \mathrm{~N}=72)$ and non-professionals $(41 \% \mathrm{~N}=82)$.

Table 1. One-way ANOVA- education on religiosity

\begin{tabular}{llllll}
\hline Source & Sum of Squares & Df & Mean Square & F & Sig. \\
\hline Between Groups & 194.71 & 3 & 64.90 & 2.54 & .05 \\
Within Groups & 5008.07 & 196 & 25.55 & & \\
Total & 5202.78 & 199 & & & \\
\hline
\end{tabular}

Table 1 shows that education of parents significantly influenced religiosity $[F(3,196)=.25, p=.05]$. Post hoc analyses using the Fisher's LSD indicated that participants whose parents were SSCE holders $(\mathrm{M}=21.82$, S.D. 4.89) were more religious than those whose parents' educational qualification were either $\mathrm{HND} / \mathrm{BSC}(\mathrm{M}=19.72$, S.D. $=4.92)$ or $\mathrm{MSC} / \mathrm{Ph} . \mathrm{D} .(\mathrm{M}=19.18$, S.D. $=5.88)$. However, there was no significant difference between the religiosity of participants whose parents were SSCE holders and NCE/OND holders $(\mathrm{M}=21.26$, S.D. $=4.74)$.

Table 2. One-way ANOVA- parental occupation on religiosity

\begin{tabular}{llllll}
\hline Source & Sum of Squares & Df & Mean Square & F & Sig. \\
\hline Between Groups & 258.880 & 2 & 129.440 & 5.16 & .007 \\
Within Groups & 4943.900 & 197 & 25.096 & & \\
Total & 5202.780 & 199 & & & \\
\hline
\end{tabular}

Table 2 shows that parent's occupation significantly influenced religiosity $[\mathrm{F}(2,197)=5.16, \mathrm{p}=.007]$. Post hoc analyzes using the Fisher's LSD indicated that participants whose parents were professionals $(\mathrm{M}=18.24$, S.D. $=$ 6.0) were less religious than those whose parents were either less professionals $(M=21.07$, S.D. $=4.41)$ or nonprofessionals $(\mathrm{M}=20.80$, S.D. $=4.90)$. However, there was no significant difference between the religiosity of participants whose parent's occupation was non-professional and less professional.

Table 3. One-way ANOVA- parental income on religiosity

\begin{tabular}{llllll}
\hline & Sum of Squares & df & Mean Square & F & Sig. \\
\hline Between Groups & 243.904 & 3 & 81.301 & 3.213 & .024 \\
Within Groups & 4958.876 & 196 & 25.300 & & \\
Total & 5202.780 & 199 & & \\
\hline
\end{tabular}

Table 3 shows that parental income significantly influenced religiosity $[F(3,196)=3.21, p=.02]$. Post hoc analyzes using the Fisher's LSD indicated that participants whose parental income were below $\$ 100,000(\mathrm{M}=$ 22.10, S.D. $=4.37)$ were more religious than those whose parental income were more $\$ 100,000(\mathrm{M}=19.27$, S.D. $=5.23$ ).

\section{Discussion}

Based on the knowledge that SES may influence the level of religiosity, the current study examined whether SES 
will influence the level of religiosity in a sample of Nigerian undergraduates. Specifically, we examined the significant difference in the level of religiosity between those with low and high socio-economic background. Our results supported the first hypothesis that SES (on the three dimensions) did have a significant influence on the level of religiosity. The study specifically revealed and supported the notion that those who are at the lower level of SES have a higher level of religiosity than those who are higher on SES. These results confirmed the theoretical postulations of the rational choice theory of religion by Stark and Bainbridge (1996) and further illustrated and demonstrated by McBride (2016). In this theory, religions are viewed as a system of compensators while human beings are viewed as rational actors making best choices, and calculating the costs and benefits in the process. Compensators here are practises or body of languages that compensate for some physical lack or frustrated goals. The main summary of this theory is that compensation controls the choice that the rational actors make. These choices are rational in the sense that they are centred on the satisfaction of wants. The religious beliefs are compensations for the failure to achieve the original goals. The less fortunate people in the society are mostly drawn to a deeper level of religiosity to compensate for their lack and material inadequacies (Aslam, 2014; Abdussalam, Johari, \& Alias, 2015). People with higher income may experience less insecurity and stress and consequently less need for social support that participation in religious activities can offer, and even the expected psychological benefits that religiosity can offer (Brewer et al., 2014).

\subsection{Implications of Findings}

The current study affirms the significant differences between the students with low SES and those with high SES on level of religiosity. Specifically, higher level of religiosity was found with the participants with low SES. A major implication of these findings is that low SES may predispose feeling of insecurity which may spur an individual to seek solace and comfort in religious participation. Another implication is that religiosity is an instrument of coping with life challenges and difficulties, which could be the more reason why undergraduates with lower socio-economic backgrounds are more religious.

\subsection{Recommendations}

Religion often support the social structures and practises that contribute towards inequality and conflict in the society. In the developed countries where there is high regard for life and dignity for one another, where people are not seen as objects of exploitation and there is regard for materialism, religion plays a vital role in the development and maintenance of a vital and just economy. This is unlike in a developing country where religion seems to make people depend on spiritual forces for solutions to life problems rather than taking pragmatic approaches in overcoming socio-political challenges.

Based on the results of the findings of the current study, it is thus recommended that there is a need for developing countries to advocate for an objective, practical and aggressive approach to solving socio-economic problems of the nation in addition to using the religious approach. This study also recommends that further research in this area should investigate on gender differences, self esteem and other psychosocial factors that could mediate the role of SES on religiosity.

\subsection{Limitations of the Study}

Despite the advantage of the current research, the findings are, however, limited to the investigation of the religiosity of Christian students only even though other types of religion are practised in the country. There is also a limitation of having a sample size from only one university in Nigeria.

\section{Conclusion}

Despite the shortcomings of this study, the prediction of the relative deprivation hypothesis, which states that life difficulties and adversaries predispose people to religiosity was confirmed. This study confirmed the significant influence of SES on religiosity. Specifically, the study was able to confirm that experiencing low SES may predispose individuals to higher religiosity level.

\section{Competing Interests Statement}

All authors declare that they have no conflict of interest.

\section{References}

Abdussalam, O. I., Johari, F., \& Alias, M. (2015). Is Zakah effective in alleviating poverty in a Muslim society? A case study of Kwara state, Nigeria. GJAT, 5(1), 33-41. https://doi.org/10.7187/GJAT762015.05.01

Action Aid Nigeria. (2015). Corruption and poverty in Nigeria: A report, Action Aid, Abuja.

Aslam, M. N. (2014). Role of Islamic Micro-finance in poverty alleviation in Pakistan: An empirical approach. 
International Journal of Academic Research in Accounting, Finance and Management Sciences, 4(4), 143-152. https://doi.org/10.6007/IJARAFMS/v4-i4/1288

Ayegbe, U. S. (2015). Unemployment and poverty as sources and consequence of insecurity in Nigeria: The Boko-haram insurgency revisited. African Journal of Political Science and International Relations, 9(3), 90-99. https://doi.org/10.5897/AJPSIR2014.0719

Baker, E. H. (2014). Socio-economic status, definition. The Wiley Black-well Encyclopaedia of Health, illness, behaviour and society. Wiley online library. https://doi.org/10.1002/9781118410868.wbehibs395

Beyes, J. (2014). The effect of religion on poverty. HTS Teologiese Studies/Theological studies, 70(1), 1-8. https://doi.org/10.4102/hts.v70i1.2614

Brewer, G., Robinson, S. J., Sumra, A., \& Tatsi, E. (2014). The influence of religious coping and religious social support on health behavior, health status and health attitudes in a British Christian sample. Journal of religion and health.

Businelle, J. I., Castrol, Y., Mullen, P. D., Velasquez, M. M., Cofta-Woerpel, L., Cinciripni, P. M., ... \& Wetter, D. W. (2013). Pathways linking socio-economic status and postpartum smoking relapse. Annals of behavioural medicine, 45(2), 180-191. https://doi.org/10.1007/s12160-012-9434-X

Fassbender, I., \& Leyendecker, B. (2018). Socio-economic status and psychological well-being in a sample of Turkish Immigrant mothers in Germany. Frontier Psychology. https://doi.org/10.3389/fpsyg.2018.01586

Gallergher, S., \& Tierney. (2013). Religiousness/religiosity. In J. Ricks (Eds.), Encyclopedia of behavioural medicine. New York: Springer.

Gallup organisation. (2009). The gallup poll briefing. Washington, D.C.

Gebauer, J. E., Sedikides, C., \& Neberich, W. (2012). Religiosity, social self-esteem, and psychological adjustment: On the cross-cultural specificity of the psychological benefits of religiosity. Psychological Science, 23, 158-160. https://doi.org/10.1177/0956797611427045

Goodman, R. (1999). The extended version of the strengths and difficulties Questionnaire as a guide to Child psychiatric caseness and consequent burden. Journal of child psychology and psychiatry, and allied disciplines, 40, 791-7999.

Hogue, N., Khan, M. A., \& Mohammad, K. D. (2015). Poverty alleviation by Zakah in a transitional economy: a small business entrepreneurial framework. Journal of Global Entrepreneurship Research, 5(7), 1-20. https://doi.org/10.1186/s40497-015-0025-8

Ighadalo, A. (2012). Poverty and sustainable socio-economic development in Africa: The Nigeria Experience. European Scientific Journal, 8(26), 51-65.

McBride, M. (2016). A rational choice theory of religious authority. Rationality and Society. Sage publications. https://doi.org/10.1177/1043463116658870

Koenig, H. G. (2012). Religion, Spirituality and health: The research and clinical implications. International Scholarly Research Network (ISRN), Psychiatry, 1-33. https://doi.org/10.5402/2012/278730

Koenig, H. G., \& Bussing, A. (2010). The Duke University Religion Index (DUREL). A five - Item measure for use in Epidemiological studies. Religions, 1, 78-85. https://doi.org/10.3390/rel1010078

Kumar, N., Gupta, N., \& Kishore, J. (2012). Kuppuswamy's socio-economic scale: Updating income rangesfor the year 2012. Indian J. public health, 56, 103-4. https://doi.org/10.4103/0019-557X.96988

Kuppuswamy, B. (1981). Manual of Socio-economic status (Urban) (1st ed., pp. 66-72). Delhi: Manasayan.

Plouffe, R. A., \& Tremblay, P. F. (2017). The relationship between income and life satisfaction: Does religiosity play a role? Personality and individual differences, 109, 67-71. https://doi.org/10.1016/j.paid.2016.12.044

Stark, R., \& Bainbridge, W. S. (1996). “Theory of religion”. Rutgers University press.

Taiwo, J. N., \& Agwu, M. N. (2016). Problems and prospect of poverty alleviation programmes in Nigeria, International Journal of Business and Management Review, 4(6), 18-30.

Tomalin, E. (2018). Religion, poverty reduction and global development institutions Palgrave Communications, 4, 132

Ucha, C. (2010). Poverty in Nigeria: Some dimensions and contributing factors. Global Majority E-Journal, 1(1), 46-56. 


\section{Copyrights}

Copyright for this article is retained by the author(s), with first publication rights granted to the journal.

This is an open-access article distributed under the terms and conditions of the Creative Commons Attribution license (http://creativecommons.org/licenses/by/4.0/). 